\title{
Challenges of Digital Twin in High Value Manufacturing
}

\author{
Singh $S^{a .1}$, Shehab $E^{a}$, Higgins $N^{b}$, Fowler $K^{b}$, Tomiyama $T^{a} \&$ Fowler $C^{b}$ \\ ${ }^{\text {a }}$ Cranfield University, College Road, Cranfield, Bedford UK \\ ${ }^{\mathrm{b}}$ Airbus Operations Ltd., Filton, Bristol UK
}

\begin{abstract}
Digital Twin (DT) is a dynamic digital representation of a real-world asset, process or system. Industry 4.0 has recognised DT as the game changer for manufacturing industries in their digital transformation journey. DT will play a significant role in improving consistency, seamless process development and the possibility of reuse in subsequent stages across the complete lifecycle of the product. As the concept of DT is novel, there are several challenges that exist related to its phase of development and implementation, especially in high value manufacturing sector. The paper presents a thematic analysis of current academic literature and industrial knowledge. Based on this, eleven key challenges of DT were identified and further discussed. This work is intended to provide an understanding of the current state of knowledge around DT and formulate the future research directions.
\end{abstract}

\section{Introduction}

DT is a set of virtual information that fully represents a potential or actual physical product used to understand, predict and optimize the performance of the physical product [1]. The concept DT has been introduced by Grieves at the University of Michigan in 2002 [2], refereeing it as the conceptual ideal for the Product Lifecycle Management (PLM). The potential of DT is further realised by NASA in 2012 defining it as a multiphysics, multi-scale, probabilistic simulation of a system used to mirror the life of an aircraft based on the best available physics models, sensor updates, fleet history data, etc. [3].

The DT can be identified by its three main pillars i) a physical product in real space, ii) a virtual product in virtual space and iii) the connection of data and information which ties together these two spaces [4][1]. DT will play a significant role in improving consistency, seamless development processes and the possibility to reuse in subsequent stages along the complete lifecycle [5]. Physical products are not limited to the industrial assets like engine or machine, they can be extended to the set of several assets like entire manufacturing facility in the high value manufacturing sector [6]. The high value manufacturing industries such as aerospace, automotive and power generation are working restlessly to build their DT visualisation tools using technologies such as virtual reality and augmented reality. Earlier, it was difficult for the enterprise to adopt such higher digital capabilities due to high computing storage and bandwidth cost. Today, the lower costs and improved power capabilities resulted in enabling Information and Communication Technology (ICT) world leaders to combine Information Technology (IT) and Operational Technology (OT) to create and use of DT for industrial applications [7]. The integrated systems based on the large data generated due to complex product lifecycle can be mirrored in the form of DT defining the boundary of real physical system and data associated to it. The data based upon the best available models, sensor updates and historical conditions, are used to mirror the life of corresponding twin [3].

The real and virtual systems would be connected to a single DT platform goes through four phases: creation, manufacturing, operation (sustainment/support) and disposable phase to create tangible business outcomes [8] [2]. DT has the ability of real-time control and optimisation of product and production lines in manufacturing environments [9], but the cost of developing and maintaining DT must be driven by both business and economic model of the industry [10]. The high value manufacturing industries share different goals in terms of business and economic models. They focus not only on financial performance but also to deliver the highest value to the country, to stakeholders, to their employees and to their business itself [11]. As mentioned by Alfanso [10], industries should focus on the digital ethics issues raised by different parties sharing data with its partners, customers and enterprise itself. Therefore, the value and contribution of data to business and partners are of utmost importance for driving value among high value manufacturing industries in the present digital transformation.

The hype about the DT in the market raises the questions related to its development with the present technological tools and skill sets, as well as implementation in current industrial infrastructure and regulatory frameworks. There are some obvious overlaps between definition of DT, portfolio management tools such as PLM \& Product Data Management (PDM) and simulation-based tools. The systems like PLM and PDM store and release huge amount to product/process data coming from multiple authorising tools and sources [5]. DT has the capability of using this data and make available for phases specific simulations tasks within the lifecycle. DT carries and stores substantial information required for succeeded phases in the lifecycle. DT encapsulates software object/model that mirrors the physical object and perform simulation and analytics based on this digital information [5]. The integration of DT with PLM/PDM is still a wide area of research. Talking about simulation and simulation tool, DT is more than a simulation. Simulation is a definitive part of DT [12]. Using design, simulation, manufacturing and analytics software, users can create and validate model-based DTs for their products and production process. DT exists only until there is an interaction between virtual platform and physical system. The state-of-the-art simulation technologies such as discrete event simulation, block orient simulation approach-MATLAB/Simulink and Finite Element Method (FEM) based simulation tools are actively used in the industry [13]. One major drawback with all these tools and systems is the flexibility, as they are

Page 1 of 10

$09 / 16 / 2018$ 
developed for the specific field of application. DT concept is capable of providing this flexibility by integrating these simulation tools along with design data, manufacturing data and analytics software to provide desired outcomes. This integration is the current focus of the researchers and industries around the world.

Despite decreasing ICT tools costs, the emergence of digital transformation and wide vision of DT, there are still several challenges which are associated with its development and implementation. The present work is a literature review-based assessment of these challenges in current high value manufacturing industries.

\section{Identifying the Challenges of DT}

DT creates many unique and complex challenges which need to be addressed and managed to ensure its large-scale benefits. A literature review on DT was conducted to understand the challenges that need to be addressed. Due to its global popularity and highly beneficial impacts, DT is gaining the attention of academia and industries worldwide. Therefore, the literature review must be comprised of the academic papers and industrial knowledge base available. Academic papers that provide the definition of DT were identified [2],[3],[5],[14],[15],[1] and text referencing to definition of digital twin [6],[16],[7],[17],[18] were transferred to QSR nVivo for further analysis. Using similar approach as Harvey [19], a word frequency query was performed on the text to identify the 75 most frequently occurring words used to describe DT (refer Appendix A) and these words were grouped into five different 'themes'

- $\quad$ Engineering

- Commercial

- Technology

- Data

- Others

Within these themes, eleven keywords/expressions were identified (see Table 1): System engineering, standards, scalability, information sharing, cost and time, cyber-physical system, data, supply chain, user interaction and ICT regulation \& digital security. The keywords are intended to characterise the key challenges of DT associated with its development and implementation in high value manufacturing. This subdivision was based on the author's interpretation of the academic literature in this area.
Table 1. Top 75 most frequently used word in definitions of DT

\begin{tabular}{|c|c|c|c|c|}
\hline Engineering & Commercial & Technology & Data & Others \\
\hline 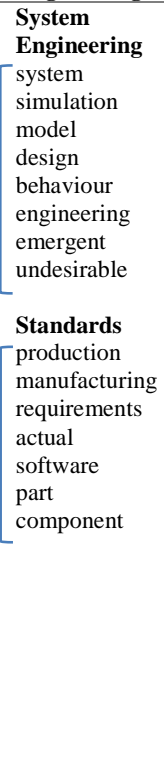 & $\begin{array}{l}\text { Scalability } \\
\begin{array}{|l}\text { product } \\
\text { process } \\
\text { development } \\
\text { space } \\
\text { components } \\
\text { vehicles } \\
\text { materials } \\
\text { lifecycle } \\
\text { create } \\
\text { computing }\end{array} \\
\text { Information } \\
\text { Sharing } \\
\begin{array}{|l}\text { information } \\
\text { use } \\
\text { companies }\end{array} \\
\text { Sector } \\
\text { servitisation } \\
\begin{array}{|l}\text { value } \\
\text { business } \\
\text { performance } \\
\text { industrial } \\
\text { industry } \\
\text { service } \\
\text { maintenance }\end{array}\end{array}$ & 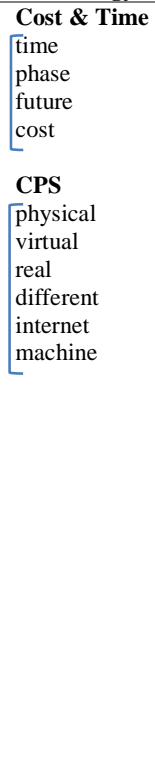 & $\begin{array}{l}\text { Data } \\
\begin{array}{|l}\text { process } \\
\text { current } \\
\text { sensor } \\
\text { acquisition } \\
\text { available } \\
\text { Form } \\
\text { phases } \\
\text { analysis } \\
\text { structural } \\
\text { analytics } \\
\text { complexity } \\
\text { structure }\end{array}\end{array}$ & $\begin{array}{l}\text { Supply Chain } \\
\begin{array}{|l}\text { complex } \\
\text { management } \\
\text { asset } \\
\text { cycle }\end{array} \\
\text { User interaction } \\
\begin{array}{l}\text { technology } \\
\text { using } \\
\text { changes } \\
\text { human } \\
\text { applications } \\
\text { operation } \\
\text { environment }\end{array} \\
\text { ICT } \\
\text { Regulation \& } \\
\text { Digital security } \\
\text { test } \\
\text { need } \\
\text { life } \\
\text { specific } \\
\text { possible } \\
\text { conditions }\end{array}$ \\
\hline
\end{tabular}

The thematic analysis provides i) an up-to-date account of complementary academic and industry-based available knowledge about DT and ii) characterisation of key challenges of DTs during their development and implementation phase.

\section{DT Themes and Key Challenges}

In the following sections, each key challenge is described along with a discussion of how it is manifested in the current literature and industrial knowledge.

\section{Engineering Challenges}

\section{Complex System Engineering}

The manufacturing industries often operate in the uncertain and constantly changing environment as per variations in customer demands, product design and processing technologies [10]. The uncertainty adds up with the restriction of flow of technologies, communications and data by evolving legislation and differences across borders [20]. Such uncertainties increase complexities in the manufacturing systems. To deal with such complexity, more complex systems are required. The complex systems are defined with the complicated nexus of vast components, communications channels and sophisticated information processing which make system predictions difficult [21][1]. The classical sequential system engineering works with the physical objects in the manufacturing environment. The process of converting a design into prototype was not only expensive with the low margin of corrections, but the cost of getting it wrong and having to go back and redesign was also expensive and timeconsuming. The DT has the ability to change this traditional approach with its ability to model and simulate digitally.

Working with digital models in the creation phase is cheaper and faster as this shows that downstream functions can influence design. Apart from such advantages, DT implementation models need more

Page 2 of 10 
maturity, conceptual details, and integration across the lifecycle and fast iterations, addressing the shortcoming of the present system engineering models. As per the workshop report by System-NET [22], system engineering brings multiple challenges to adapt to new working environments. In the report experts also agree that future system engineering environments should support evolutionary development, merging of systems, handling complexity and analysis of system properties.

\section{Standards}

Small-scale industries often have their own systems for communicating, accessing data online and storing data. In high value manufacturing industries like aerospace, automotive and manufacturing markets, the standards need to be followed so as to ensure efficient third-party communication, product and human safety, as well as adequate data security and structural integrity [23]. Development of standards and standards-based interoperability is important and challenging at the same time for the evolution of industry 4.0 and Internet of Things (IoT) based industrialisation [20]. As proprietary formats are dangerous on the industrial level, product data formats that lock in DT raise questions related to standards [24]. The DT is enabled by and support other critical digital technologies including IoT and big data analytics [25]. DT ties together the valuable information about the products and operations based on IoT based smart connected products and systems. At the moment, the IoT standardisation is an aforementioned alphabet soup [23]. The global state of play for IoT standards is marred by definitive lack of integration and alignment, as well as lack of actors considering broad picture [20].

Organisations like Society of Automotive Engineers (SAE) International are still in the process of standardising IoT to resolve issues related to data (such as ownership, governance, interoperability, management, security) and digital products and certification [23]. Therefore, IoT standardisation is critical for the DT to achieve maximum benefits.

\section{Commercial Challenges}

\section{Scalability}

The manufacturing industries often face compatibility and scalability issues while tying together their software chain to form an entire suite of PLM or Enterprise Resource Planning + Manufacturing Execution System (ERP+MES) or more integrated tools. The scalability itself concerns as a major research challenge for implying application of cocreative approaches and methodologies for value creation on axiological level along with co-creative based design and management on operational levels. Therefore, besides the functional aspect of scalability, in terms of social concerns, it can be featured as an instrument for value increase [26]. For DT, designing the virtual copies of the physical manufacturing, scalability is one of the important model properties [27]. As the various definitions of scalability given in terms of architecture, data load, ability to change the level of parameters, supply chain complexity, horizontal expansion, computational ability and architecture scalability tend to be a key issue for the DT [26]. The scope of DT may vary from a simple product to highly complex processes or manufacturing system offering desired accuracy based on smart data analytics. Therefore, system architectures need to be scalable in terms of problem size function along with respect to IT profile and range of viable instantiations desired capacities. This shows the necessity of more scalable system architectures for the development and implementation of DT.

Not only the system side, scalability can be one of the most important characteristics for establishing virtual side of DT. For example, in an architecture for "self-configurable large-scale virtual manufacturing environment for collaborative designers", scalability is counted as one of the eight important characteristics of Large-Scale Virtual Environments (LSVE) and Virtual Manufacturing Environment (VME) [28]. In modern design environments, complex CAD systems must be downwardly scalable due to the enormous amount of memory and processing implied by visualisation of complex objects [29].

\section{Information Sharing}

The data sharing can be segmented into two: internal data sharing and external data sharing. The internal data sharing refers to pooling of data from different departments within the single company and external data sharing takes place among the stakeholders across the supply chain. In high value manufacturing the information sharing across the value chain bring tangible benefits and transparency. In the modern manufacturing, information sharing may be one of the biggest hurdles as it is derived from company policies, cultural and people's mindset about data ownership. Thus, this becomes a major challenge beyond the technology and engineering complexities for DT. System architects and framework developers often lack the confidence to come up with more integrated ideas due to complexities of information sharing. For an integrated system like DT, both internal and external data sharing is important. The policy reforms related to data sharing are timeconsuming and follow the complicated procedures due to proprietary and data security concerns. The mindset of people engaged and cultural differences for data sharing are hard to change and eliminate even though the overall benefit along the value chain is the only concern.

The lack of information sharing may result in data silos. Data silos tend to arise in organisation because different department shares different goals, priorities and responsibilities. For example, Maintenance, Repairs and Overhaul (MRO) data picture in the aviation industry doesn't lie with any one type of organisation. Operators, lessors, airports, OEMs and MRO providers each holds a piece of puzzle, making industry collaboration a mandatory step toward capitalising on digital-data driven opportunities. But the ingrained culture of risk avoidance, security and IP concerns has stunted attempts at data sharing [30].

\section{Sector Servitisation}

The manufacturing and service industries are upgrading their portfolio to increase the value of services, fostering and productisation of business by integrating products and services together [31]. Servitisation concerns manufacturers by adding services to the products that would otherwise be offered in the downstream position in the value chain system [32]. As these services-based enterprises develop further, the potential of digital technology to optimise service at a system level increases. With the advent of selling the product as a service e.g. aircraft engine manufacturers providing "power by hour" engine solutions, has contributed a major portion of their revenues [33]. Here, DT has the ability to deliver warnings, predictions and optimisations are enough on the basis of continuously learning and

Page 3 of 10 
improving the models based on advanced analytics of real-time and historical data of the asset [34].

The servitisation has their own challenges based on organisational structure, business model, development process, customer management and risk management [35]. Servitisation is being driven by even more complex customer needs and a need to defend against product competition particularly from lower cost economies [36]. For example, the manufacturing industries recognise that delivering services is more complex than manufacturing products and require different approaches to product- service design, organisational strategy and transformation. Industries should pay attention to these challenges and complexities while developing and implementing DT. Industries also need to evaluate the impact, benefits and ideal application of DT in their service business model and across the value chain.

\section{Technology Challenges}

\section{Cost and Time}

The high value manufacturing industries are coming up with new business models to adapt in the phase of industrial digitalisation. For a high value framework, the company's added value score and the categorisation according to cost and revenue are strongly focussed. Cost is the critical factor to maintain the value among stakeholders and company [11]. To drive value from DT, new business and economic models will be required considering development costs, as well as ongoing DT maintenance requirements. The DT is known for its complex issues along with the benefits. Complex assets will often comprise of multiple twins, organised into large composite/universal twin [37][10]. Due to such complexity, separate development, integration and deployment cost analysis will be required at each layer of composite twin to satisfy the business requirements from different users [10]. This reflects the complexity of the system is detrimental to cost-effectiveness of the DT. The higher cost of IT environments is one of the main difficulties in the course of realisation of DT as an essential precondition of Cyber-Physical Production System (CPPS) [15].

The consistency of data and information sharing among stakeholders across the supply chain are the fundamental validity of DT. Therefore, the digitalisation of supply chain is one of the key aspects of its functionality. The digitalisation of supply chain is not easy as it will take considerable efforts in terms of time taken in adequate technologies development, time taken in breaking cultural barriers and mindset related to data sharing, as well as financial investments in software and services [38].

The cost and time related serious concerns in regard to DT has been mentioned by experts like Marc Halpern in PDT Europe conference in Gothenburg, that there's naivety about the possibility of bringing together DT concepts in terms of cost and time. He also mentioned that it will take longer and be more resource consuming than anyone can imagine bringing the possible solutions of DT together. The COCOMO II analysis [39] of U.S. Air Force [40] claims that the cost of software development and sustainment of digital thread and DT will cost in multiple trillions of dollars to achieve end-to-end capability across the aircraft lifecycle. It also claimed that there may take a couple of hundred years to turn this big vision into reality.

\section{Cyber-Physical System (CPS)}

CPS is a convergence of several complementary technologies including a broader view of the CPSs, IoT and internet of service that can play a vital role in enabling enterprises to achieve their business goals [41]. CPS is also recognised by Alam [42] as the next generation of IoT, computation, communication and control features of the physical systems get distributed and physical devices act as data sources for the computation modules i.e. DT. Hence, it is clear that major challenges during the development and implementation of DT come from the major issues related to the broader perspective of CPS.

As Industrial Cyber-Physical System (ICPS) enable monitoring and control of physical processes and bridge the cyber and virtual worlds, their impact across the value chain is increasingly evident. The emerging paradigms for implementing ICPSs, such as Service Oriented Architecture (SOA), cloud computing, IoT, big data and the industrial internet need to be deeply investigated, especially in realworld operations [41]. ICPS is built on highly heterogeneous hardware and software components. It also depends on systems and services that are operated by third-party stakeholders. The study of the lifecycle of these components is very crucial and creating the synergies among their stakeholders, especially in a cross-domain manner, can be considered as the major challenges. The cross-cutting challenges related to ICPS are also discussed by Colombo [41].

\section{Data Challenges}

\section{Data: Variety, mining, big data and ownership}

With the shift of manufacturing industries from production-oriented manufacturing to selling services as products, chapters for product development need to be rewritten. The manufacturing industries are realising the potential of data generated during product development and manufacturing operations to drive innovation and value creation. DT utilises this data to define the boundaries of physical and virtual systems to simulate and optimise manufacturing core operations. Even though the concept of DT seems perfect, but the issues related to data is one of the most serious concern.

In the present manufacturing cloud, the variety of data generated across the lifecycle is massive. Starting with product development, design data in terms of 2D, 3D drawings are very different from the Finite Element Analysis (FEA) and other simulation data. The manufacturing data is structured in completely different formats from design and engineering. The systems like PLM and SAP/ERP can be considered as an organised form of such a wide variety of data. There still lack a bridge that how these systems can be used for a single integrated platform as DT. Such a large variety of data raises the data integration, data cleansing and data fusion issues [4]. The literature shows that researchers have utilised machine data on shop floor, design data, structural damage tolerance data to build their respective twins, but clearly lack ways of integrating them into one. This may seriously hinder the development of ideal architectures and frameworks for DT. Some of the scenarios on shop floor reflect its uncertainties and can only be managed based on user experiences and situational response to uncertainties. This form of data is hard to record or store digitally.

As the data is collected from various streams of product development and manufacturing, it needs to be stored in databases, accessed and processed to transform them into valuable information for virtual space. As data mining is one way of finding possible useful patterns from the present databases [43], therefore it is potentially a key factor 
for improving the status of virtual spaces in DT. First, the large variety of data during manufacturing results in bigger and complex databases which makes data mining difficult [43]. Second, data mining is not very often utilised in manufacturing. Less than $10 \%$ of the users solve issue in manufacturing by applying data mining [43]. Third, the DT models work on the continuous improvement of virtual models based on the real-time data. The data mining algorithms are only limited to the production, fault diagnosis and maintenance of the assets in the manufacturing environment. When talking about DT, data mining has the potential of leveraging data across the complete product lifecycle, but the scope is still unclear. Fourth, the data mining for the converging behaviour of physical and virtual spaces in DT need further attention of researchers.

One of the major problem related to data in DT is the convergence of the big data. Data governance is extremely important for success of big data projects [44]. As DT is closely linked to big data acquisition, processes and analytics, convergence of increasing data generated due to system and data storage results in issues related to it [45]. ]. Research predicts that half of all big data projects will fail to deliver against their expectations. The 6 V's definition of big data given by Demrikan [44] gives a clear picture of data. Big data involves the collection of data sets that are so large and complex that it becomes difficult to process using hands-on database management tools or traditional data processing applications. This might result in a possible difficulty related to data management and utilising captured data in DT. The concepts like Data Lake [46] have been recently welcomed by the enterprises to help capture and store their large amounts of raw data on many different scales at low cost [44]. Using Data Lakes, enterprises can perform data management transformation, processing and analytics based on specific application. Even though Data Lake is suitable for data ingestion, transformation, federation, batchprocessing and data discovery, it still needs some data governance and technology integration reforms [44].

The issue of data ownership rises with the personal data of an individual in today life in the present ecosystem of smart connected devices. The question of who owns the data collected from smart watches, smart-thermostats, etc., is indeed far from resolved and the ecosystem is currently developing in legal vacuum. Hence, data ownership raises serious concerns of deep ethical and financial implication and cyber protection of individuals. Talking at the industrial level, data ownership is a serious concern in the present digital transformation which makes it critical for DT as well. With the shift of product oriented to the service-oriented business model, the responsibility and reliability of the product become the responsibility of the product manufacturer. DT has the potential of playing important role in this shift by sharing data across the value chain. This raises the questions related to data security and ownership. The DT represents increasing intellectual capital with the time as more information is added, which further raises the concern for the enterprises.

\section{Other Challenges}

\section{Supply Chain}

The consistency of data and information sharing are the fundamental validity of DT. It requires greater coordination of operating practices and standards and data architecture flexible enough to fulfil future requirements [25]. To fully enable and visualise the contribution of DT in product development, manufacturing and during rest of the product lifecycle, the digitalisation of the supply chain is very important [47]. However, this aspect is new and holds its own challenges at the present scenario. Data integration is the primary driver behind the smart supply Page 5 of 10 chain, enabling analysis of both structured and unstructured data from both internal and external sources to give deeper insights into the supply chain [38]. Therefore, all the data streams need to be consolidated to deliver a single source of truth.

The digitalisation of the supply chain is not easy as it will take considerable efforts and financial investment in software and services if the aim is to achieve the true end-to-end integration and visibility across the complete supply chain [38]. For example, the aerospace manufacturers like Airbus has more than 12,000 suppliers [48] worldwide in their multi-tier supply chain. As each supplier works in their own enterprise ecosystem with certain technological capabilities, therefore end-to-end integration across the supply chain can be difficult. While thinking about digitalising supply chain and embedding platforms like DT in it, one should think about what values it will bring among the suppliers.

\section{User Interaction}

Human interaction is the one key aspect in the development and implementation of DT in the manufacturing environment. Human actions and interactions with machines in the production environment are prone to accidents, thus involve safety concerns on the shop floor. The production shop floor is still sustained by many manual operations based upon human interactions. Unlike technical systems, human employees cannot be precisely monitored. In CPPS, all devices are connected to each other to create additional information and services leaving no space for the human involvement in the decision making. Presently if an employee wants to actively take part in the decisionmaking process, the complete system has to wait for human inputs into the system. It is possible if an employee takes part in exchanging (gathering and distributing) information and answering requests for technical systems.

According to Poehler [49], one way to make it possible is by a development of DT for humans. Through human DT, immediate user feedback can be generated and used for computational decisions by production system. This might not be enough as the data set is limited to skills, experience and preferences of the user. The researcher still lacks more influences on user decision especially indirect influences like mood, character, which are crucial in the modern manufacturing environment.

\section{ICT regulations and digital security}

In the present industrial digitalisation, ICT has become tightly integrated with all the industries, changing from a support function to production system. Manufacturing processes continue to evolve in the context of industry 4.0 with greater adoption of cloud computing, development of IoT and deeper integration of physical and software components. This evolving infrastructure is ideal for the systems like DT in manufacturing. Such a boost in innovation also raises certain policy and regulatory challenges which may slow down the development of DTs in their industrial space. These include protecting competition and consumers, managing security and privacy risks and promoting interoperability and transparency [20]. Therefore, the current policies and frameworks need to be assessed to address these challenges. The highly strict and regulated phenomena of export control [50] [51] which ensures safeguarding technical capabilities and product theft, may also divest industries to attain considerable openness or freedom of technology and information sharing across the geographical borders. Therefore, export control regulations are critical. 
DT is based on massive, cumulative, real-time and real-world data measurements across an array of data, therefore data security is critical [7]. In the digital economy, individual personal data, financial data, new technology development data and business and strategic information of the organisation are at stake. Data security threats and incidences coming from breach of cyber security are growing in numbers and sophistication with significant consequences. These can affect organisation's image, finances and even physical assets itself [20]. The frequent data breaches in this digital economy may lead to damage reputation of the organisations. As per the Economic Intelligence Unit Survey (2013) [20] of business leaders, only one in four companies reports an extensive awareness of digital risk across the organisation. This gap is becoming a public policy challenge for Small and Medium Enterprises (SMEs) and high value manufacturing industries potentially. The legal frameworks often fail and considered last resort to address digital security among industries due to lack of flexibility to address an extremely dynamic area [20]. Especially for DTs, as an issue raised by Halpern [24]., "Digital Twin represents increasing intellectual capital as the years go by, as more information is added to it. How can this be secured?"

\section{Conclusion and Outlook}

The aim of this paper is to characterise the key development and implementation challenges of DT, based on the current literature and industrial knowledge base. These challenges show that hype for DT in the industry is on the higher side than the actual realisation, which is the key validity of this paper.

The maturity of DT is directly subjected to time and cost. Literature shows that the key challenge of time and cost is hard to quantify. The time and cost for DT development and implementation depend upon the scale and complexity of other challenges concluded. Therefore, industries should start with a minimum level of product or process complexity to get maximum productivity. To address the challenges associated with complex system engineering and ICPS, both researchers and industries will play a vital role. New research-based architectures and frameworks for DT are actively required that can be implemented into current systems and industrial internet. The industries should promote such research initiatives by investing more in research and development.

The challenges associated with scalability, supply chain and sector servitisation tends to be more industry focussed. The manufacturing industries should understand that how they can embrace the phase of digitalisation as per their present infrastructure. Industries should closely assess that whether DT is required to optimise their operations and functions. If yes, what would be the impact on their overall business model and outcome? DT for supply chain can help to predict the uncertainties and mitigating challenges of current supply chain system.

The complexity of data along the product lifecycle in manufacturing is immense and integrating it into a single system like DT is difficult. If DT is the ultimate goal, large variety of data during manufacturing process will need more integrated tools and systems. This results in a sudden pressure on software and application development industries along with the researchers. The data issues in manufacturing related to big data and its convergence force industries to change their traditional way of storing and dealing with data.

The challenges like digital standardisation, information sharing, ICT regulation and digital security need a global governance and policy maker's attention. New policies, regulations and business strategies are required to overcome the silos of data sharing and perseverance. Along with the government governing bodies, regulatory bodies like European Committee for Standardization-European Committee for Electrotechnical Standardization (CEN-CENELEC), European Telecommunications Standards Institute (ETSI) in Europe, globally acting International Electrotechnical Commission (IEC), International Organization for Standardization (ISO) and International Telecommunication Union (ITU) will play an important role in standardisation of digital manufacturing [20]. The scope of benchmarking such standards in digital manufacturing will still require a clear scope of DT across the value chain.

As per the author's best knowledge, this paper has presented the first qualitative approach for identifying the key challenges of DT in high value manufacturing. Eleven key challenges of DT have been identified based on word frequency thematic analysis of current literature and industrial knowledge. Some challenges are obvious and explicit, whereas others are less tangible. These are intended to further our understanding about DT and how can increasing complex nature of emerging digital manufacturing be managed by DT implementation.

\section{References}

1. Kahlen, F., Flumerfelt, S. and Alves, A., Transdisciplinary Perspectives on Complex Systems: New Findings and Approaches. Springer International Publishing. Springer International Publishing, Switzerland, 2017, doi:10.1007/978-3319-38756-7.

2. Grieves, M. and Vickers, J., "Digital Twin: Mitigating Unpredictable, Undesirable Emergent Behavior in Complex Systems (Excerpt)," 2016, doi:10.13140/RG.2.2.26367.61609.

3. Glaessgen, E.and Stargel, D., "The Digital Twin Paradigm for Future NASA and U.S. Air Force Vehicles." In 53rd AIAA/ASME/ASCE/AHS/ASC Structures, Structural Dynamics and Materials Conference 20th AIAA/ASME/AHS Adaptive Structures Conference 14th AIAA, 2012, doi:10.2514/6.20121818.

4. Tao, F. and Zhang, M., "Digital Twin Shop-Floor: A New ShopFloor Paradigm Towards Smart Manufacturing." IEEE Access 5: 20418-27, 2017, doi:10.1109/ACCESS.2017.2756069.

5. Hehenberger, P. and Bradley, D., Mechatronic Futures. 1sted. Springer International Publishing, 2016, doi:10.1007/978-3-31932156-1.

6. Bouchard, J., "Digital Twin: Identical but Different." Oliwer Whyman. Accessed May 23, 2018 http://www.oliverwyman.com/content/dam/oliverwyman/global/en/2016/oct/Digital Twins_Identical but Different.pdf.

7. Parrott, A. and Lane,W., "Industry 4.0 and the Digital Twin." Deloitte Ltd. Accessed May 23, 2018. https://www2.deloitte.com/insights/us/en/focus/industry-40/digital-twin-technology-smart-factory.html\#endnote-2.

8. Ammermann, D. "SAP-Digital Twin Implementation." SAP SE. Accessed April 1, 2018 https://blogs.sap.com/2017/09/09/digital-twin-implementation/.

9. Zhong, R., Xu, X., Eberhard K. and Stephen, N., "Intelligent Manufacturing in the Context of Industry 4.0: A Review." Engineering 3 (5). Elsevier Publishing Company: 616-30, 2017, doi:10.1016/J.ENG.2017.05.015.

10. Pettey, C., "Prepare for the Impact of Digital Twins." Smart with Garntner, Gartner Inc. Accessed May 23, 2018. https://www.gartner.com/smarterwithgartner/prepare-for-theimpact-of-digital-twins/. 
11. Livesey, F., 2006. "Defining High Value Manufacturing." Institute of Manufacturing, Cambridge University. Cambridge, UK.

http://www2.ifm.eng.cam.ac.uk/cig/documents/DefiningHVM.p df.

12. Wesserman, S., "What Is the Digital Twin and Why Should Simulation and IoT Experts Care?." Accessed May 10, 2018. https://www.engineering.com/DesignSoftware/DesignSoftware Articles/ArticleID/16070/What-is-the-Digital-Twin-and-WhyShould-Simulation-and-IoT-Experts-Care.aspx.

13. Schluse, M., Rossmann, J., "From simulation to experimentable digital twins: Simulation-based development and operation of complex technical systems." ISSE 2016. International Symposium on Systems Engineering - Proceedings Papers, 2016, doi:10.1109/SysEng.2016.7753162.

14. Funk, K. and Reinhart, G., "Digital Twins at the Crossroad of Production, Product and Technology." In MikroSystemTechnik 2017; Congress, 1-4. Munich, Germany: VDE.

15. Uhlemann, T., Lehmann, C. and Steinhilper, R., "The Digital Twin: Realizing the Cyber-Physical Production System for Industry 4.0." In Procedia CIRP, 61:335-40. Elsevier B.V, 2017, doi:10.1016/j.procir.2016.11.152.

16. GE Digital(b), "The Digital Twin: Compressing Time to Value for Digital Industrial Companies." Accessed May 23, 2018. https://www.ge.com/digital/sites/default/files/The-DigitalTwin_Compressing-Time-to-Value-for-Digital-IndustrialCompanies.pdf.

17. Mikell, M. and Clark, J., "Cheat Sheet: What Is Digital Twin?" Accessed May 10, 2018. https://www.ibm.com/blogs/internetof-things/iot-cheat-sheet-digital-twin/.

18. I-Scoop, "Digital Twins - Rise of the Digital Twin in Industrial IoT and Industry 4.0." Accessed May 10, 2018. https://www.iscoop.eu/internet-of-things-guide/industrial-internet-things-iiotsaving-costs-innovation/digital-twins/.

19. Harvey, C. and Stanton, N., "Safety in System-of-Systems: Ten Key Challenges." Safety Science 70. Elsevier: 358-66, 2014, doi:10.1016/j.ssci.2014.07.009.

20. OECD, "Key Issues for Digital Transformation in the G20." Berlin, Germany, 2017, https://www.oecd.org/internet/keyissues-for-digital-transformation-in-the-g20.pdf.

21. Mitchell, M. and Toroczkai, Z., "Complexity A Guided Tour." Physics Today, 2010, doi:10.1063/1.3326990.

22. Styles, G., Kalawsky, R., "Research Top Challenges for MBSE in Industry 4.0 and IoT", 2015, doi: 10.13140/RG.2.1.4556.7767

23. Wesserman, S., "SAE to Create Standards for IoT, Big Data and the Digital Twin in the Aerospace Industry." Accessed May 10, 2018. https://www.engineering.com/IOT/ArticleID/16278/SAEto-Create-Standards-for-IoT-Big-Data-and-the-Digital-Twin-inthe-Aerospace-Industry.aspx?e_src=relart.

24. Ogewell, V., "Digital Twins: Beware of Naive Faith in Simplicity." Accessed May 23, 2018. https://www.engineering.com/PLMERP/ArticleID/16272/Digital -Twins-Beware-of-Naive-Faith-in-Simplicity.aspx.

25. Aerospace Technology Institute, "Insights- Digital Transformation." Accessed May 10, 2018. http://www.ati.org.uk/wp-content/uploads/2017/09/ATI-

INSIGHT-01-Digital-Transformation.pdf.

26. Putnik, G., Sluga, A., Elmaraghy, H., Teti, R., Koren, Y. et al., "Scalability in Manufacturing Systems Design and Operation: State-of-the-Art and Future Developments Roadmap." CIRP Annals - Manufacturing Technology 62 (2). CIRP: 751-74, 2013, doi:10.1016/j.cirp.2013.05.002.

27. Zhang, H., Liu, Q., Chen, X., Zhang, D. et al., "A Digital TwinBased Approach for Designing and Decoupling of Hollow Glass
Production Line." IEEE Access 3536 (c): 1-1, 2017, doi:10.1109/ACCESS.2017.2766453.

28. Lee, H., Banerjee, A., "A self-configurable large-scale virtual manufacturing environment for collaborative designers." Virtual Reality. Springer15(1): 21-40, 2011, doi: DOI:10.1007/s10055009-0151-0.

29. Baladi, M., Vitali, H., Fadel, G., Summers, J., et.al., "A taxonomy for the design and evaluation of Networked Virtual Environments: its application to collaborative design." International Journal on Interactive Design and Manufacturing (IJIDeM). Springer 2(1): 17-32, 2008, doi: 10.1007/s12008-0070032-2.

30. Capgemini, "Digital Aviation: MRO Innovation and Disruption." Accessed Spetember 9, 2018. https://www.capgemini.com/wpcontent/uploads/2017/11/capgemini_digital-aviation-mroinnovation-and-disruption-report_nov-2017.pdf.

31. Boukhris, A., Fritzsche, A. and Möslein, K, "Co-Creation in the Early Stage of Product-Service System Development." Procedia CIRP. Elsevier (63): 27-32, 2017, doi: 10.1016/j.procir.2017.03.316.

32. Neely, A., "Exploring the Financial Consequences of the Servitization of Manufacturing." Operations Management Research 1 (2): 103-18, 2007, doi:10.1007/s12063-009-0015-5.

33. Connerty, M., Navales, E., Kenney, C. and Bhatia, T., "Manufacturing Companies Need to Sell Outcomes, Not Products." Harvard Business Review. Accessed May 23, 2018. https://hbr.org/2016/06/manufacturing-companies-need-to-selloutcomes-not-products.

34. GE Digital, "Digital Twin At Work: The Technology That's Changing Industry." Accessed january 25, 2018. https://www.ge.com/digital/blog/digital-twin-work-technologychanging-industry.

35. Zhang, W. and Banerji, B., "Challenges of Servitization: A Systematic Literature Review." Industrial Marketing Management $65 \quad$ (March): 217-27, 2017, doi:10.1016/j.indmarman.2017.06.003.

36. Baines, S., Lightfoot, H., Benedettini, O., Kay J., "The servitization of manufacturing: A review of literature and reflection on future challenges". Journal of Manufacturing Technology Management. Emerald 20(5): 547-567, 2009, doi: 10.1108/17410380910960984.

37. Yun, S., Hong, J. and Kim, W., "Data-Centric Middleware Based Digital Twin Platform for Dependable Cyber-Physical Systems." In International Conference on Ubiquitous and Future Networks, ICUFN, 922-26. Milan: IEEE, 2017, doi:10.1109/ICUFN.2017.7993933.

38. Pwc- Strategy\&, "Connect and Optimize: The New World of Digital Operations." Accessed January 26, 2018. https://www.strategyand.pwc.com/media/file/Connect-andoptimize.pdf.

39. Boehm, B., Clark, B., Devnani-Chulani, S., Horowitz, S. et al., "COCOMO II Model Definition Manual." Center for Software Engineering, USC. Vol. 4, 2000, doi:10.1525/nr.2000.4.1.6.

40. West, T. and Blackburn, M., "Is Digital Thread/Digital Twin Affordable? A Systemic Assessment of the Cost of DoD's Latest Manhattan Project.” In Procedia Computer Science, 114:47-56. Elsevier B.V, 2017, doi:10.1016/j.procs.2017.09.003.

41. Colombo, A., Karnouskos, S., Kaynak, O., Shi, Y. et al., "Industrial Cyberphysical Systems: A Backbone of the Fourth Industrial Revolution." IEEE Industrial Electronics Magazine, 2017, doi:10.1109/MIE.2017.2648857.

42. Alam, K. and Saddik, A., "C2PS: A Digital Twin Architecture Reference Model for the Cloud-Based Cyber-Physical Systems." IEEE Access 5: 2050-62, 2017, doi:10.1109/ACCESS.2017.2657006.

Page 7 of 10 
43. Vazan, P., Janikova, D., Tanuska, P., Kebisek, M. et al., "Using Data Mining Methods for Manufacturing Process Control." IFAC-PapersOnLine 50 (1). Elsevier B.V.: 6178-83, 2017, doi:10.1016/j.ifacol.2017.08.986.

44. Tyagi, P. and Demirkan, H., "Data Lakes: The Biggest Big Data Challenges." Accessed May 23, 2018. http://analyticsmagazine.org/data-lakes-biggest-big-data-challenges/.

45. Tao, F., Zhang, M. and Cheng, J., "Digital Twin Workshop: A New Paradigm for Future Workshop." Comput.Integr.Manuf.Syst 23 (1): 1-9, 2017, doi:10.13196/j.cims.2007.01.001.

46. Miloslavskaya, N. and Tolstoy, A., "Big Data, Fast Data and Data Lake Concepts." 7th Annual International Conference on Biologically Inspired Cognitive Architectures, BICA, 88:300 305. Elsevier B.V, 2016, doi:10.1016/j.procs.2016.07.439.

47. Elliott, C., "A Digital Twin for the Supply Chain." Accessed May 23,2018 .

https://www.esri.com/about/newsroom/publications/wherenext/d igital-twin-for-supply-chain-management/.

48. Airbus, "Be an Airbus supplier.” Accessed Spetember 09, 2018. https://www.airbus.com/be-an-airbus-supplier.html.

49. Graessler, I. and Poehler, A., "Integration of a Digital Twin as Human Representation in a Scheduling Procedure of a CyberPhysical Production System.” IEEE International Conference on Industrial Engineering and Engineering Management, 289-93. Singapore: IEEE, 2018, doi:10.1109/IEEM.2017.8289898.

50. Zhang, Q. and Zhang, H., "Can Export Control Win the Competition Edge of a Country' S High Technology Sector : Based on the View of the Enterprise to Recoup the Capital Outlay." 20th International Conference on Management Science \& Engineering, 1128-33. Harbin, China: IEEE, 2013, doi:10.1109/ICMSE.2013.6586416.

51. Cook, J. and Cook, K., "U.S. Government Export Control Reform Initiative-What's Going On?" IEEE Aerospace Conference Proceedings, 1-8. Big Sky, MT, USA: IEEE, 2013, doi:10.1109/AERO.2013.6496860.

\section{Acknowledgment}

The present work is accomplished in collaboration of Cranfield University and AIRBUS Operations Ltd, UK. The project is registered under Engineering and Physical Sciences Research Council (EPSRC) ICASE Studentship (2017) and supported by EPSRC National Productivity Investment Fund and AIRBUS, UK.

EPSRC is a British Research Council that provides government funding for grants to undertake research and postgraduate degrees in engineering and the physics, mainly to universities in the United Kingdom. Whereas, AIRBUS is a European Multinational Corporation that designs, manufactures and sells civil and military aeronautical products worldwide.

\section{Definitions/Abbreviations}

$\begin{array}{ll}\text { DT } & \text { Digital Twin } \\ \text { PLM } & \text { Product Lifecycle Management } \\ \text { ICT } & \begin{array}{l}\text { Information and Communication } \\ \text { Technology }\end{array} \\ \text { IT } & \text { Information Technology }\end{array}$

Page 8 of 10
Internet of Things

Society of Automotive Engineers

Large Scale Virtual

Environments

VME

Virtual Manufacturing

Environment

MRO

Maintenance, Repairs and Overhaul

CPPS

Cyber-Physical Production System

SOA

Service Oriented Architecture

FEA

Finite Element Analysis

SME

Small and Medium Enterprise

\section{CEN-CENELEC}

European Committee for Standardization-European Committee for Electrotechnical Standardization

ETSI

IEC

European Telecommunications Standards Institute

International Electrotechnical Commission

ISO

International Organization for Standardization

ITU
International Telecommunication Union 


\section{Appendix-A}

Table A-1 represents the work frequency query analysis report:

Table A- 1. QSR word frequency query report

\begin{tabular}{|c|c|c|c|}
\hline Word & Length & Count & Weighted Percentage (\%) \\
\hline system & 6 & 389 & 1.54 \\
\hline data & 4 & 299 & 1.18 \\
\hline physical & 8 & 267 & 1.05 \\
\hline information & 11 & 168 & 0.66 \\
\hline product & 7 & 158 & 0.62 \\
\hline virtual & 7 & 152 & 0.60 \\
\hline time & 4 & 140 & 0.55 \\
\hline simulation & 10 & 137 & 0.54 \\
\hline model & 5 & 132 & 0.52 \\
\hline production & 10 & 131 & 0.52 \\
\hline manufacturing & 13 & 125 & 0.49 \\
\hline real & 4 & 122 & 0.48 \\
\hline design & 6 & 107 & 0.42 \\
\hline process & 7 & 100 & 0.39 \\
\hline behaviour & 8 & 98 & 0.39 \\
\hline use & 3 & 98 & 0.39 \\
\hline life & 4 & 92 & 0.36 \\
\hline engineering & 11 & 85 & 0.34 \\
\hline development & 11 & 76 & 0.30 \\
\hline space & 5 & 73 & 0.29 \\
\hline value & 5 & 72 & 0.28 \\
\hline complex & 7 & 71 & 0.28 \\
\hline components & 10 & 68 & 0.27 \\
\hline phase & 5 & 68 & 0.27 \\
\hline business & 8 & 65 & 0.26 \\
\hline management & 10 & 65 & 0.26 \\
\hline test & 4 & 65 & 0.26 \\
\hline performance & 11 & 64 & 0.25 \\
\hline vehicle & 7 & 62 & 0.24 \\
\hline future & 6 & 60 & 0.24 \\
\hline industrial & 10 & 58 & 0.23 \\
\hline technology & 10 & 58 & 0.23 \\
\hline requirements & 12 & 57 & 0.23 \\
\hline cycle & 5 & 56 & 0.22 \\
\hline different & 9 & 54 & 0.21 \\
\hline industry & 8 & 54 & 0.21 \\
\hline materials & 9 & 54 & 0.21 \\
\hline
\end{tabular}

Page 9 of 10

$09 / 16 / 2018$ 


\begin{tabular}{|c|c|c|c|}
\hline emergent & 8 & 53 & 0.21 \\
\hline lifecycle & 9 & 53 & 0.21 \\
\hline using & 5 & 53 & 0.21 \\
\hline internet & 8 & 52 & 0.21 \\
\hline operation & 9 & 52 & 0.21 \\
\hline need & 4 & 50 & 0.20 \\
\hline create & 6 & 47 & 0.19 \\
\hline processes & 9 & 45 & 0.18 \\
\hline current & 7 & 44 & 0.17 \\
\hline sensor & 6 & 44 & 0.17 \\
\hline specific & 8 & 44 & 0.17 \\
\hline undesirable & 11 & 44 & 0.17 \\
\hline service & 7 & 43 & 0.17 \\
\hline actual & 6 & 41 & 0.16 \\
\hline companies & 9 & 41 & 0.16 \\
\hline cost & 4 & 41 & 0.16 \\
\hline acquisition & 11 & 40 & 0.16 \\
\hline available & 9 & 40 & 0.16 \\
\hline form & 4 & 40 & 0.16 \\
\hline phases & 6 & 40 & 0.16 \\
\hline changes & 7 & 39 & 0.15 \\
\hline human & 5 & 39 & 0.15 \\
\hline analysis & 8 & 38 & 0.15 \\
\hline structural & 10 & 38 & 0.15 \\
\hline asset & 5 & 37 & 0.15 \\
\hline software & 8 & 37 & 0.15 \\
\hline part & 4 & 36 & 0.14 \\
\hline environment & 11 & 35 & 0.14 \\
\hline machine & 7 & 35 & 0.14 \\
\hline analytics & 9 & 33 & 0.13 \\
\hline maintenance & 11 & 33 & 0.13 \\
\hline possible & 8 & 33 & 0.13 \\
\hline complexity & 10 & 32 & 0.13 \\
\hline component & 9 & 32 & 0.13 \\
\hline structure & 9 & 32 & 0.13 \\
\hline applications & 12 & 31 & 0.12 \\
\hline computing & 9 & 31 & 0.12 \\
\hline conditions & 10 & 31 & 0.12 \\
\hline
\end{tabular}

Page 10 of 10 
2018-10-30

\title{
Challenges of digital twin in high value manufacturi
}

\author{
Singh, Sumit
}

SAE International

Singh S, Shehab E, Higgins N, et al., (2018) Challenges of digital twin in high value

manufacturing. SAE Technical Papers, Article number 2018-01-1928

https://doi.org/10.4271/2018-01-1928

Downloaded from Cranfield Library Services E-Repository 